\title{
WORLD ENGLISHES AND THEIR IMPLICATIONS FOR UNIVERSITY EDUCATION
}

\author{
Beáta Biliková \\ Applied Languages Faculty, University of Economics in Bratislava, Slovakia \\ beata.bilikova@euba.sk \\ Katarína Seresová \\ Applied Languages Faculty, University of Economics in Bratislava, Slovakia \\ katarina.seresova@euba.sk
}

\begin{abstract}
Over the past few decades, the notion of World Englishes has achieved much attention among linguists, language teachers, and other professionals. The present study explores the impact these trends have had on university education in the field of English philology and culture, focusing on the study programmes run by the Applied Languages Faculty, the University of Economics in Bratislava, Slovakia. Our research was designed to gain insights into the students' perception of varieties of English and identify those areas which require more attention in order to provide students with the most relevant content. The research sample contained 130 students of one BA and one MA programme. Our research was based on a questionnaire which provided us with the data on students' awareness of the studied issues. The data were subsequently processed using combined quantitative and qualitative methods. One part of the data was statistically analysed with regard to the frequency of certain aspects. The second part was analysed focusing on students' attitudes and evaluative statements. Results of the analysis indicated both the key tendencies in their thought and the orientation of the occasional excentric views. The research outcomes enabled us to establish several important facts, e.g. a relatively insufficient understanding of the relevant terminology and concepts, high awareness of the existence of varieties of English, and, simultaneously, low awareness of the features distinguishing those varieties, etc. The conclusions point out those areas which should be represented more extensively in our curricula to reflect the actual current situation in the English language.
\end{abstract}

Keywords: World Englishes; variety; university education; competence.

\section{Introduction}

The discussion on the internal fragmentation of English at the time of its triumph as a global language started more than 20 years ago. The notions such as 'World Englishes' or 'regional varieties of English' achieved a lot of attention among linguists, academics, language teachers, and other involved professionals. There is no doubt that the global process of reshaping the body of English, which has been evolving over the past few decades, marks a shift to a different paradigm of treating the English language. There has been much talk on the relation between the widely acknowledged standard forms of English and the regional varieties as well as on the status of the regional varieties that have recently been steadily gaining in significance. These circumstances necessarily pose a question concerning the extent to which the current academic education, particularly in the field of English philology and culture, takes into consideration the new reality of diversification within the English language. Our research was designed to examine the levels of our university students' awareness of the fact that there exist different varieties of English, spoken and written across the world. Furthermore, it intends to shed light on both the sources of such awareness and the degree of their understanding of this phenomenon's various aspects. We approached our research motivated by the wish to gain some valuable insights into how relevant information reaches university students of English philology and culture and, at the same time, how they manage to cope with it. Ultimately, we hoped to collect data that would help us modify the current study programmes and curricula in such a way that they best reflect the actual situation in the English language development and respond to the existing condition of social practice.

\section{Literature review}

Summing up the prospects of the English language for the $21^{\text {st }}$ century, in 1997 the British linguist David Graddol (1997) wrote that "we have entered a period in which language and communication will play a more central role than ever before in economic, political and cultural life - just at the moment in history that a global language has emerged" (p.3). Analysing the impact of the rise of global Englishes on English language teaching (ELT), Rose and Galloway (2019) focused on the aspect of teacher education and proposed to use the term GELT, i.e. Global English language teaching, rather than ELT. Evaluating their

(C) Beáta Biliková, Katarína Seresová. 2021. Published by Igor Sikorsky Kyiv Polytechnic Institute. This is an Open Access article distributed under the terms of the licence CC BY 4.0 
publication, Andrew Blair (2020) emphasises the fact that they make "repeated calls for a paradigm shift and a GELT ideology to supplant those associated with standard language and native speaker norms" (p. 1145).

In 2019 Galloway and Numajiri published an article examining the representation of Global English component in postgraduate TESOL and Applied Linguistics programmes. Their research involved selected universities from the UK, the USA, Sweden, Norway, Italy, Turkey, Vietnam, Japan, China, and Australia. Having analysed the attitudes of future teachers of English, the authors arrived at the conclusion that „GELT curricular innovation is complex, particularly due to the conceptual transition that it requires, but this should not deter TESOL practitioners from considering the relevance of GELT for their contexts" (p.140).

The condition of English as a global language was also explored in detail by Jenkins $(2007,2014)$ and Seidlhofer (2013) who - apart from other things - forced the reader to re-evaluate the traditional concepts of English language instruction and assessment. In a review of B. Seidlhofer's monograph Understanding English as a Lingua Franca (2013) it is stated that Seidlhofer makes a case for "reconsidering the old constructs of language variety, community, and competence, replacing preoccupation with the processes of adoption and conformity with a focus on adaptation and creativity" (p.315).

Seen from the perspective of mutually contradictory trends shaping the way English developed as a global language, it had become evident even before the turn of the century that the English language was likely to encounter some unexpected and unforeseeable twists and turns. This view was explored by Phillipson (2003) or Crystal (1997). The newly acquired status of a global language, it was felt, was not necessarily going to last or even achieve further growth in influence as the factor of economy, that undeniably fuels spreading of any language it operates on, signalled the rise of several other competing languages which might have claimed some of the territories at that point dominated by English. Similar views appeared in the writings of Graddol (1997, 2006), Ostler (2005), and Crystal (1997).

These contradictory trends in the development of the English language result in a situation that can be characterised by two premises. On the one hand, if the English language is to keep the status of a global language, it has to retain particular rules and standards, securing its ability to function as an effective means of communication across the world. Seyranyan and Westphal (2020) assert that the concept of World Englishes ,poses a challenge to English language teaching (ELT) in countries where English does not have an official status (i.e. there is no codified local norm) and is learned as a foreign language, such as Armenia or Germany. Learners of English in these countries are norm-dependent on 'standard' Englishes spoken as a native language" (p.2). On the other hand, the growing number of people embracing English as a second language causes the influx of culturally, historically, or geographically specific elements into the English language which gives rise to fragmentation of the body of English and boosts the growth of its diversity. Deriving from these circumstances, in 1985 Kachru introduced the concept of World Englishes and focused on the research into the relation between Asia's Englishes and World Englishes (2000).

Discussing the diversity within the English language, Leimgruber (2013) uses an alternative term and explains that "since the 1980s, when research interest in the field of 'World Englishes' began to gather speed, the view of the English language around the world has been largely dominated by the construct of socalled 'varieties' of English. These varieties are usually given a geographical label ('Singapore English', 'Welsh English', 'South African English', 'Fiji English', etc), and are described in terms of their pronunciation, their grammar, and their vocabulary" (p.3). The issue is frequently referred to in the works of Schneider (2003), Jenkins (2007; 2014), Ostler (2005), and Seargeant (2012), Cenoz (2019), Alptekin (2012) too. The impact of World Englishes on ELT is further discussed by Maurais (2006) and Mohr, Jansen, and Forsberg (2019) who conducted an interesting research examining the prospects of European English as the variety of English to be taught to children at German and Swedish schools.

\section{Aim and hypothesis}

The present study is aimed at exploring the impact that World Englishes have had on university education in the field of English philology and culture, focusing on the study programmes run by the Applied Languages Faculty, the University of Economics in Bratislava, Slovakia. Having become acquainted with the research of Galloway and Numajiri (2019) which concentrated on the examination of Global English element in teacher-training postgraduate programmes, we considered it useful to explore the situation in non-teachertraining programmes run by the Applied Languages Faculty, University of Economics in Bratislava, Slovakia. The relevant study programmes focus on English philology and culture and they are naturally expected to offer our students up-to-date information and effective training in specific features and functions of contemporary English. However, they do not provide a targeted, systematic presentation of the World Englishes issue. Our research was designed to gain insights into the students' perception of varieties of 
English and is intended to identify those areas which might require more attention in order to provide students with the most relevant content possible.

It was assumed that, along with the expansion of the Internet, growth of social networks, and the flourish of communication technologies in general, young people were being increasingly exposed to language production in miscellany of diverse Englishes. Such exposure was believed to have cultivated students' sensitivity to linguistic variability and improved their orientation in this study area. As the research was carried out on a sample of university students specialised in English language and culture, it was launched with a conviction that a correlation would be discovered between the number of years (semesters) of study and the level of understanding of the researched issues.

\section{Research design}

Our research project was based on a short questionnaire designed to explore our university students' awareness of the diversity within the English language and identify not only their sources of information but also the actual level of linguistic competence within the context of World Englishes. The online questionnaire was administered via MS Forms and it included 10 questions, both open and closed. The data collection took place over the period of two weeks, January 18-29, 2021. The students were sent the link to the questionnaire via email and they used the MS Forms platform to submit it anonymously.

\section{Instruments and procedure}

The online questionnaire consisted of 10 questions. The first one asked whether or not the students were aware of the existence of different regional varieties of English and it also explained that the term variety did not equal the notion of dialect. Next, the questionnaire asked when and how they found out about World Englishes, giving students options to choose from (at primary or secondary school, from teachers, from friends, from the media, etc.). The question four asked how many varieties of English they were able to distinguish by hearing and they were given 3 options: none, 1 or 2 , and 3 or more. The fifth question required students to name the varieties of English they can distinguish. Next, we asked if students thought it was useful/important to have some knowledge of World Englishes. The following two questions were directed at students' awareness of the variety of English they were learning at primary and secondary schools. The question 9 asked if they knew which variety of English they used themselves. And finally, we asked if they would like to learn about World Englishes more.

The collected data were subsequently analysed and individual segments were compared. The results of analyses were then interpreted and represented in the form of charts and graphs.

\section{Data analysis}

The research included both quantitative and qualitative methods. Quantitative data were statistically processed by MS Forms application and analysed with regard to the frequency of certain aspects. Qualitative data (open-ended responses) were evaluated and analysed with the focus on students' attitudes and evaluative statements. The final phase of data processing was represented by a comparative analysis of responses from students of different grades and interpretation of the obtained results.

\section{Research sample}

As it has already been suggested, the research sample contained university students of both bachelor and masters non-teacher-training programmes of the Applied Languages Faculty, University of Economics in Bratislava, Slovakia. All involved students are specialising in English language and culture.

Participating in the research was voluntary, therefore not all students eventually submitted the filled-in forms, which accounts for the final number of 130 respondents (79 BA students and $51 \mathrm{MA}$ students). The total number was constituted by 35 students of the $1^{\text {st }}$ year BA programme, 34 students of the $2^{\text {nd }}$ year BA, 10 students of the $3^{\text {rd }}$ year BA, 21 students of the $1^{\text {st }}$ year MA, and 20 students of the $2^{\text {nd }}$ year MA.

\section{Ethical issues}

The research was conducted in compliance with the regular ethical standards of research. It was voluntary and anonymous. Students were provided with the link to the online questionnaire with the explanation that participation is a matter of their free choice. They were also informed that the identity of individual respondents is impossible to determine and no consequences could follow their decision not to participate or the particular opinions they would express when taking part. 


\section{Results}

The questionnaire results showed that $80 \%$ of our students are aware of the existence of World Englishes. The remaining $20 \%$ are not familiar with that notion, which appears to be quite a large number, considering the fact that the students in question specialise in the English language and culture.

Reporting on the time when they became aware of the existence of World Englishes, 20\% of students indicated primary school period, $44 \%$ chose the secondary school period, and as many as $19 \%$ claim to have learnt about the varieties of English at university only. An interesting fact here is that while the BA students (years 1, 2, and 3) report to have reached the awareness mainly at secondary school $(54 \%, 59 \%$, and $50 \%$ respectively), the responses of MA students are much more evenly distributed between secondary school and university $\left(1^{\text {st }}\right.$ year MA $-33 \%$ vs. $38 \%, 2^{\text {nd }}$ year MA $-30 \%$ vs. $\left.45 \%\right)$ which may suggest that secondary schools have been gradually adopting new trends in ELT and using them effectively in order to provide students with the most up-to-date materials and learning strategies. Such conclusion, however, would have to be confirmed by a more extensive and representative study, involving a larger number of respondents and preferably covering a longer period of time.

Next, we focused on the source of information on and awareness of the existence of World Englishes. The most influential factors here proved to include school teachers and the media.

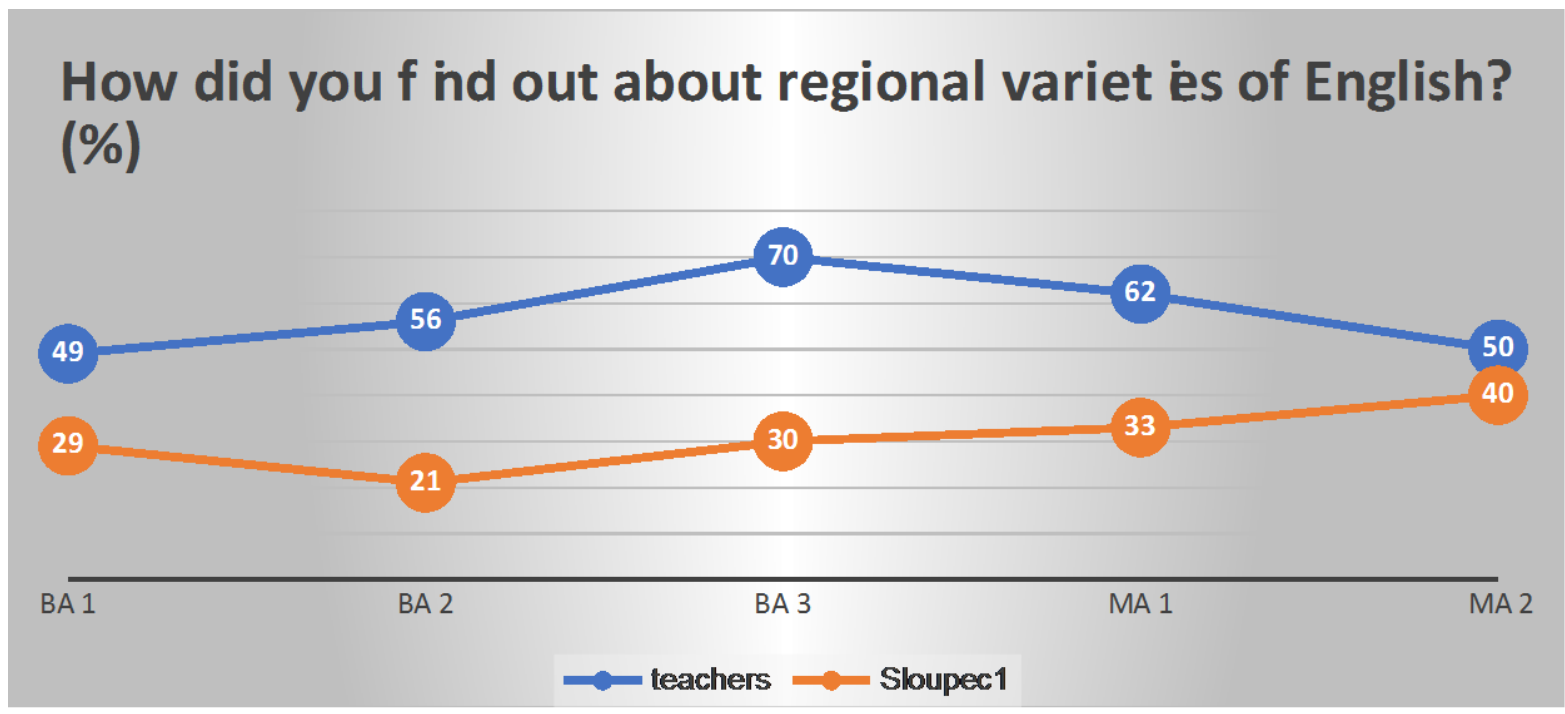

Figure 1. Percentage of students in individual years of study who found out about varieties of English through school teachers (blue) and the media (orange).

Both the factor of teachers and that of the media seem to be weaker in the category of bachelor students, especially the first two years. This condition can be interpreted as a sign of a possible trend towards a broader spectrum of influences that shape the way young people use and treat English learnt as a foreign language. More significance seems to be taken over by the factor of friends and the factor labelled as 'other' which was selected by $3 \%$ of involved students and some of them in the open-ended data mentioned that they had been influenced by the people they had met while travelling or playing computer games. Even though the examined interval of 5 years (the assumed maximum difference in age of the respondents) is too short to provide grounding for strong statements, we can suggest that school teachers appear to be possibly losing the position of an instructing authority No. 1, which can be demonstrated by the percentage of teachers' influence in the $3^{\text {rd }}$ year BA and all MA students as opposed to the relevant percentage in the first two years BA students.

The fourth question inquired about the number of varieties of English students can distinguish by hearing. The percentage of students who selected the option 'none' does not seem to follow any specific pattern. It ranges from $6 \%$ in the $1^{\text {st }}$ year BA, through $32 \%$ in the $2^{\text {nd }}$ year $\mathrm{BA}$, and $10 \%$ in the $3^{\text {rd }} \mathrm{BA}$, then $17 \%$ in the $1^{\text {st }} \mathrm{MA}$ and $30 \%$ in the $2^{\text {nd }}$ MA. On the other hand the responses to the option ' 3 or more' show that on average BA students are better able to distinguish more varieties of English, as the percentage in BA students is $63 \%, 35 \%$, and $70 \%$ respectively as opposed to $33 \%$ and $20 \%$ in MA students. Interestingly enough, the lowest level of competence in this area was indicated by the students of the final year of MA programme. 
Being asked to specify the varieties of English they know, students most often mentioned American and British English. Nevertheless, some also mentioned the Australian, Irish, Scottish, Canadian, or even Jamaican and South African Englishes. Some students offered such options as Cockney, Geordie or Brummie even though the first question of the questionnaire explicitly warned them not to confuse varieties of English with dialects, mentioning Cockney, Scouse, Glaswegian, and Geordie as examples of dialects.

The figure below demonstrates the percentage of students in individual years of BA and MA studies who claim to be able to distinguish 3 or more varieties of English in comparison to those who believe they cannot distinguish any variety. The two indicators are juxtaposed with the percentage of those students in individual years who would like to learn about the regional varieties of English more (green).

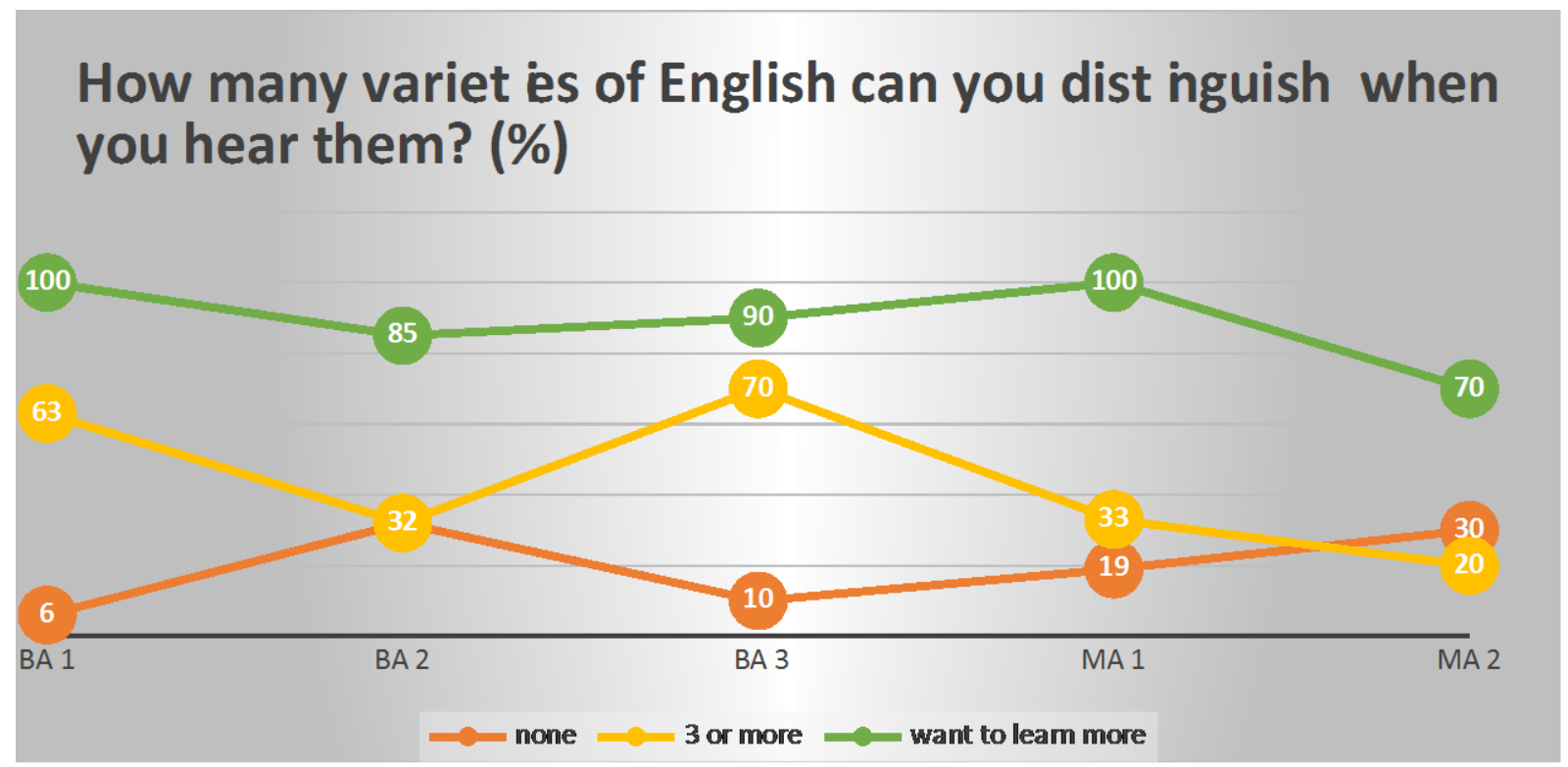

\section{Figure 2. Percentage of students according to the number of varieties of English they can distinguish (yellow, orange), in comparison to those who want to learn more (green).}

Responding to the sixth question concerning the usefulness/importance of the knowledge of World Englishes, the vast majority of respondents confirmed that they indeed considered such knowledge useful and gave sound arguments, e.g. "it is always an advantage to be able to understand properly", "some regional varieties are hard to understand, so it would help", "if we can understand others, we improve ourselves", etc. There were a few responses that did not ascribe such competence much importance, opining that "it depends - if you expect to be conversing with someone using a specific variety, then yes" or "the basic knowledge is useful, just to know that varieties exist" or "not sure if it is necessary but it surely is interesting". A few students simply typed "no, it is not important". One of the $2^{\text {nd }}$ year students was rather resolute in his/her comment, replying „no, because even though there are some differences, it is pretty similar to standard English and everybody should understand standard English". The presented examples of students' opinions prove that some students' convictions about the English language are somewhat detached from reality and might need more guidance. The point which seems to stand out in such responses is the evident insufficient understanding of relevant terminology on the part of the involved students or rarely there are even outright misconceptions.

The following two questions asked students about the variety of English they were taught at primary school and then at secondary school. It came as a little surprise that about a half of respondents either did not know or they were not sure. Other students were able to name British English as the language variety they were learning, or they at least mentioned that their textbooks were British. Some students remarked that they used textbooks with British English but their teachers used American English. Finally, one student stated that at secondary school they were learning "not a specific variety but British English". Numerous related answers, along with the last mentioned example, betray certain inconsistencies in understanding the notion of the varieties of English. It seems evident that this issue probably deserves more time and attention in order to help students gain better orientation in World Englishes and in the puzzling twists of the English language development.

The ninth question asked students if they themselves were using any specific variety of English in practical communication. Almost a half of them stated they were not aware of using any specific variety. The 
remaining students named American English, British English or a mix of the two. The most frequent reasons for using American English included such statements as "it sounds better", "it's easier to use", "I learn a lot of words from the TV series which are in American English", etc. The key arguments for using British English were "we learnt it at school" and "it is standard English". Concerning the last group of students who use a mix of British and American English, it can actually be further subdivided into two categories. Having more closely examined students' responses, we discovered that some of them claim to use American English in spoken communication - because it is simpler, and British English in written communication - because this is what they have been learning at schools, including grammar, vocabulary, idioms, etc. They appear to be splitting their use of the language into American and British sections quite consciously and intentionally. The second sub-category is represented by those students who combine different features of both British and American Englishes and, unconsciously cross-breeding the two, they create a hybrid language, containing elements which are probably easiest to employ in communication or, possibly, those which are closest to the paradigm of the students' native language use. The proposed explanations of the elements selection are not much more than speculations, of course, or informed assumptions at best. Nevertheless, what we are observing here is very likely a birth of a new variety of English - a Central-European Youth English, we might call it, which derives elements and structures from various sources and adjusts them to both the needs of its users and contexts of its use.

The last question of the questionnaire inquired if students would like to learn more about the varieties of English. $83 \%$ of the respondents answered 'yes'. The option 'no' was selected by $9 \%$ and the remaining $8 \%$ of the involved students chose not to respond to this question at all. If we take a closer look at the percentage of the respondents who answered 'yes' in individual grades, we will see it is $100 \%$ in the $1^{\text {st }}$ year BA, $85 \%$ in the $2^{\text {nd }}$ year BA, next it is $90 \%$ in the $3^{\text {rd }}$ year BA, then again $100 \%$ in the $1^{\text {st }}$ year MA and $83 \%$ in the $2^{\text {nd }}$ year MA. Even though there is no evident regular pattern in the aforementioned numbers which could help us understand the mechanism of the situation development, it certainly can be concluded that there is a vast majority of students who either find their current knowledge of World Englishes insufficient or they consider the topic so attractive, important or useful that they feel the need to expand their knowledge on the subject.

\section{Discussion}

Our research was planned and conducted in order to gain insights into the students' perception of varieties of English and specify those study areas which require more attention in order to provide students with the most relevant content. It was inspired by a similar research carried out by Galloway and Numajiri (2019) on a much larger international scale which intended to explore the attitudes of postgraduate students of teacher-training programmes to Global English language teaching concept. In our case, the research focused on the attitudes of the students of non-teacher-training programmes of one university only the University of Economics in Bratislava, Slovakia. However, the programmes in question are specialised in English philology and culture which suggests they should have an in-depth understanding of related issues.

Unlike Mohr, Jansen, and Forsberg (2019), we did not specifically concentrate on the use or study of European English as we believe the kind of philological-cultural study programme which is run by our university should embrace as a large spectrum of different varieties of English as possible.

The presented results provided us with the data implying several important facts. In the first place, it is a relatively high theoretical awareness among our students of the existence of World Englishes. On the other hand, we were slightly surprised by a relatively low practical competence of students concerning the ability to distinguish varieties of English by hearing. In this respect, we limited ourselves in the research to the students' assessment of themselves which may not provide fully objective feedback. Nevertheless, it outlines the framework within which our students perceive English in its diversity and helps us reconstruct the mental maps of the English language our students have in their minds.

One of the significant weak points which were uncovered in the course of the research is, generally speaking, an unexpectedly low level of understanding the terminology and concepts related to the World Englishes subject matter. We consider it possible that this factor to a certain extent influenced students' responses and, ultimately, the results of the present research.

Therefore, there is an apparent need to employ within our university study programmes more practise aimed at World Englishes understanding and/or even introduce specialised courses dealing with the issue. All this coincides with the nature and emphasis of the existing programmes and can significantly increase their relevance and academic weight too. It is desirable that all teachers within the possibilities include World Englishes elements in their sessions on a regular basis and target their teaching methods at conscious boosting of students' awareness as well as knowledge of the subject matter. These efforts should be 
complemented by the use of appropriate, up-to-date teaching material from a reliable source, e.g. from the specialised textbook English Around the World (Schneider, 2020) or similar.

Examining the period of time when the participating students became aware of the existence of World Englishes, the questionnaire conducted in January 2021 indicated that our current BA students found out about World Englishes predominantly at their secondary schools. On the other hand, the MA students indicated university more frequently than secondary school, the numbers of both ranging between $30 \%$ and $45 \%$. As has already been suggested, the retreat of universities as sources of primary information about World Englishes in favour of secondary schools may be ascribed to the progress in the quality of ELT at secondary schools. There is a number of top quality textbook series available which expose students to an up-to-date, progressive material reflecting the latest trends in the real-life English language, e.g. Life, English File or Market Leader. The textbooks provide both learners and teachers already at secondary schools with valuable print, audio, and video material, professional support, and guidance. An indivisible aspect of their conception is representation of the variety of Englishes in real-life communicative situations which introduces young learners to the heterogeneous universe of the English language.

Answers to the question concerning the variety of English they use themselves illuminated a remarkable fact that a number of students, unintentionally mixing British and American Englishes (and possibly elements of other Englishes too) based on the criteria of simplicity and convenience, probably contribute to the genesis of another variety of English with specifically central-European pragmatic base, shaped by the discourses of social networks, computer games, and apparently also TV series.

In the close future, a new, larger-scale research project should be launched, with a similar focus, involving additional method(s) of research, preferably interview and/or listening test, possibly some others, which can supply more detailed and reliable qualitative data. Our intention is to involve researchers and students from a larger number of universities not only from Slovakia but also from other European countries. In such a way we could obtain a complex, trustworthy view on the issue of World Englishes as reflected and represented in the context of European university education. Such research would simultaneously enable the research team to identify those teaching methods, strategies, materials, etc. which prove the highest effectiveness and compare the impact of other relevant factors on the results of the educational process.

\section{Research limitations}

The encountered limitations were of methodological type. First of all, it was the constitution of the research sample. It contained 130 students of one BA study programme and a related MA study programme, representing all relevant grades: the $1^{\text {st }}, 2^{\text {nd }}$, and $3^{\text {rd }}$ years $B A$, and the $1^{\text {st }}$ and $2^{\text {nd }}$ years MA. However, the numbers of the involved students from individual grades differed considerably (BA - 35, 34, 10 and MA $21,20)$. The reasons for such disproportionality are objective, as the absolute numbers of students in individual grades vary as well. Yet, the fact remains that it may have influenced the representativeness of the achieved results, particularly in comparative analyses.

Secondly, despite the original plan to conduct also personal interviews in addition to the questionnaire in order to enhance the qualitative data, it proved to be beyond our possibilities, given the anti-covid safety measures, the lack of students' willingness to participate in online talks in relevant numbers, and the scope of time at our hands. Subsequently, in some instances, we were left with students' assessments of themselves and their competence, without an opportunity to acquire proofs and, thus, fully reliable data.

\section{Conclusions}

The present research was designed to examine the extent to which university students specialising in the English language and culture are aware of the changes taking place within English. Other aspects we planned to observe and evaluate included the levels of understanding the English language internal diversification which has become known as 'World Englishes' or 'regional varieties of English'. Secondly, our attention was directed at the sources of relevant information which introduced the students in the given subject matter. Finally, we hoped to gain valuable insights into the students' perception of the issue and identify those areas which require more attention in order to provide our students with the most relevant content, reflect the actual situation in the English language development, and respond to the existing condition of social praxis.

Our research was approached with the hypothesis that the expansion of the Internet, growth of various social networks, and flourish of communication technologies in general, mediated young people the experience and understanding of the miscellany of diverse Englishes. We believed that such a condition cultivated students' sensitivity to linguistic variability and improved their orientation in this study area. It was also expected that a correlation would be discovered between the number of years of study and the level of understanding the researched issues. The research was carried out on a sample of 130 university students, 
both BA and MA programmes. It employed the method of a questionnaire, the results of which were subsequently analysed and evaluated with the use of both quantitative and qualitative methods.

It can be concluded that the aim of the research was reached. Through the analysis of the obtained data, we managed to achieve all formulated objectives. However, our hypotheses were proved only partially. The results did not demonstrate any evident correlation between the students' level of World Englishes understanding and the number of semesters/years of the completed study. Nevertheless, the collected data provided us with thought-provoking material, which offered valuable insights in our students' knowledge and understanding of the researched subject matter. That simultaneously uncovered the areas in which the current curricula or their implementation in educational process did not fully succeed in delivering the desired effect: mainly, the instances of students' insufficient understanding of the relevant notions and terminology, surprisingly low competence relating the students' ability to distinguish varieties of English which may suggest a partial lack of exposure to World Englishes that might lead to a thorough understanding of the given phenomenon.

The present research can be treated as a pilot study which should trigger a more extensive and more representative examination of the explored issues. It may cover students of a larger number of universities and span over a longer period of time that might provide us with significant data concerning the dynamics of the examined phenomena. We believe such research would result in improvements in the quality of university education and ultimately also in the re-evaluation of the current study programmes and curricula, thus keeping in touch with the developments and unignorable changes within the body of the English language.

References:

Alptekin, C. (2012). Understanding English as a Lingua Franca. Review. ELT Journal, 66(2), $248-251$. https://doi.org/10.1093/elt/ccs004

Blair, A. (2020). Global Englishes for Language Teaching, Rose, Heath and Galloway, Nicola. Cambridge, England: Cambridge University Press, 2019. Pp xix + 255. Review. TESOL Quarterly, 54(4), 1144-1146. https://doi.org/10.1002/tesq.586

Cenoz, J. (2019). Translanguaging pedagogies and English as a lingua franca. Language Teaching, 52(1), 71-85. https://doi.org/10.1017/S0261444817000246

Crystal, D. (1997). English as a Global Language. Cambridge: Cambridge University Press.

Dubicka, I., O’Keeffe, M. (2011). Market Leader. Third edition. Advanced Coursebook. Prentice Hall College Division.

Dummett, P., Hughes, J., Stephenson, H. (2014). Life Advanced Student's Book. National Geographic Learning.

Galloway, N. and Numajiri, T. (2019). Global Englishes Language Teaching: Bottom-up Curriculum Implementation. TESOL Quarterly, 54(1), 118-145. https://doi.org/10.1002/tesq.547

Graddol, D. (1997). The Future of English. London: The British Council.

Graddol, D. (2006). English Next. London: The British Council.

Hallett, J. (2012). English around the World: An Introduction by Edgar Schneider World Englishes by Gunnel Melchers and Philip Shaw. Reviews. World Englishes, 31(2), 268-271. https://doi.org/10.1111/j.1467-971X.2012.01757.x

Jenkins, J. (2007). English as a Lingua Franca: Attitude and Identity. Oxford: Oxford University Press.

Jenkins, J. (2014). Global Englishes: A Resource Book for Students. London: Routledge.

Kachru, B. (2000). Asia's Englishes and World Englishes. English Today, 16(1), 17-22. https://doi.org/10.1017/S0266078400011391

Latham-Koenig, Ch., Oxenden, C. (2013), English File. Advanced Student's Book. Third edition. Oxford: Oxford University Press.

Leimgruber, Jakob R. E. (2013). The trouble with World Englishes. English Today, 29, 3-7. https://doi.org/10.1017/S0266078413000242

Maurais, J. (ed.) (2006 ). Languages in a Globalising World. Cambridge: Cambridge University Press.

Mohr, S., Jansen, S., \& Forsberg, J. (2019). European English in the EFL classroom?: Teacher attitudes towards target varieties of English in Sweden and Germany. English Today, 7(1). https://doi.org/10.1017/S0266078419000403

Ostler, N. (2005). Empires of the Word: a language history of the world. London: Harper Collins.

Phillipson, R. (2003). English-Only Europe? Challenging Language Policy. London: Routledge.

Rose, H., and Galloway, N. (2019). Global Englishes and Teacher Education. Cambridge: Cambridge University Press.

Schneider, E. W. (2003). The dynamics of New Englishes: From identity construction to dialect birth. Language, 79(2), $233-81$. https://doi.org/10.1353/lan.2003.0136

Schneider, E. W. (2020). English around the World: An Introduction, $2^{\text {nd }}$ ed. Cambridge Introductions to the English Language. Cambridge: Cambridge University Press.

Seargeant, P. (2012). Exploring World Englishes: Language in a Global Context. London: Routledge.

Seidlhofer, B. (2013). Understanding English as a Lingua Franca - Oxford Applied Linguistics. Oxford: Oxford University Press.

Seyranyan, S., and Westphal, M. (2020). Attitudes of Armenian and German students toward British English, American English, and their own Englishes: The global diversity of English and the question of models of English Language Teaching. English Today, 1-9. https://doi.org/10.1017/S0266078419000543 